\title{
PARTICLE CONTROL IN THE DIII-D ADVANCED DIVERTOR
}

\author{
by \\ M.J. SCHAFFER, S.I. LIPPMANN, M.A. MAHDAVI \\ T.W. PETRIE, R.D. STAMBAUGH, J. HOGAN, \\ C.C. KLEPPER, P. MIODUSZEWSY.I, L. OWEN, \\ D.N. HILL, M. RENSINK, D. BUCHENAUER
}

NOVEMBER 1991 


\section{DISCLAIMER}

This report was prepared as an account of work sponsored by an agency of the United States Government. Neithe- the United States Government nor any agency thereof, nor any of their employees, mases any warranty, express or implied, or assumes any legal liability or responsibility for the accuracy, completeness, or usefulness of any information, apparatus, product, or proces disclosed, or represents that its use would not infringe privately owned rights. Reference herein to any specific commercial product, process, or service by trade name, trademark, manufacturer, or otherwise, does not necessarily constitute or imply its endorsement, recommendation, or favoring by the United States Government or any agency thersof. The views and opinions of authors expressed herein do not necessarily state or reflect those of the United States Government or any agency thereof. 


\title{
PARTICLE CONTROL IN THE DIII-D ADVANCED DIVERTOR
}

\author{
by \\ M.J. SCHAFFER, S.I. LIPPMANN, M.A. MAHDAVI \\ T.W. PETRIE, R.D. STAMBAUGH, J. HOGAN,* \\ C.C. KLEPPER,* P. MIODUSZEWSKI,* L. OWEN,* \\ D.N. HILL, ${ }^{\dagger}$ M. RENSINK, ${ }^{\dagger}$ D. BUChENAUER ${ }^{\ddagger}$
}

\author{
* Oak Ridge National Laboratory \\ †Lawrence Livermore National Laboratory \\ ‡Sandia National Laboratories
}

This is a preprint of a paper to be presented at the 14th Symposium on Fusion Engineering, September 30-October 3, 1991, San Diego, California, and to be printed in the Proceedings.

Work supported by

Department of Energy

Contract DE-AC03-89ER51114

GENERAL ATOMICS PROJECT 3466

NOVEMBER 1991

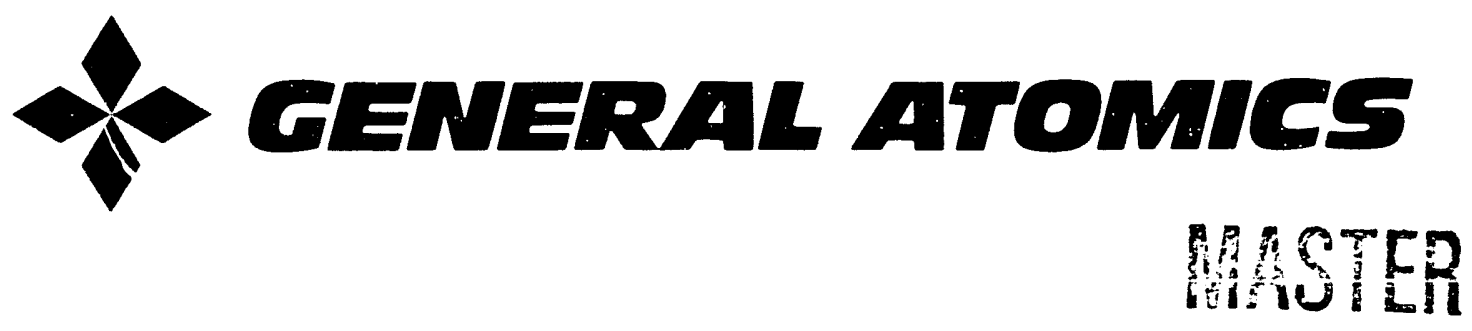




\title{
PARTILLE CONTROL IN THE DIII-D ADVANCED DIVERTOR
}

\author{
M.J. Schaffer, S.I. Lippmann, M.A. Mahdavi, T.W. Petrie, R.D. Stambaugh \\ General Atomics \\ P.O. Box 85608 \\ San Diego, California 92186-9784
}

\author{
J. Hogan, C.C. Klepper, P. Mioduszewski, L. Owen \\ Oak Ridge National Laboratory \\ Oak Ridge, Tennessee 37831
}

\author{
D.N. Hill, M. Rensink \\ Lawrence Livermore National Laboratory \\ Livermore, California 94550 \\ D. Buchenauer \\ Sandia National Laboratories \\ Livermore, California 94550
}

Abstract: A new, electrically biasable, semi-closed divertor was installed and operated in the DIII-D lower outside divertor location. The semi-closed divertor has yielded static gas pressure buildups in the pumping plenum in excess of 10 mtorr. (The planned cryogenic pumping is not yet installed.) Electrical bias controls the distribution of particle recycle between the inner and outer divertors by $\vec{E} \times \vec{B}$ drifts. Depending on sign, bias increases or decreases the plenum gas pressure. Bias greatly reduces the sensitivity of plenum pressure to separatrix position. In particular, $\vec{E} \times \vec{B}$ drifts in the DIII-D geometry can direct plasma across a divertor target and then optimally into the pumpirag aperture. Bias, even without active pumping, has also demonstrated a limited control of ELMing $\mathrm{H}$-mode plasma density.

\section{Introduction}

The poloidal divertor is presently favored for next-step, high-power tokamaks. The divertor guides a thin boundary layer of escaping plasma (scrapeoff layer, SOL) just outside the separatrix, along magnetic field lines to the divertor targets, where the plasma deposits its heat and is neutralized.

At present it is thought that the high divertor peak heat flux in tokamak reactors can be handled by oscillating the separatrix divertor intercept (strike) positions in time, in order to reduce the time averaged peak heat flux. However, it is then difficult to provide an efficient pumping geometry, where the neu ralized particles are close to the pump duct entrance and gas backstreaming is blocked by the divertor plasma. Our experiments have demonstrated exhaust augmentation by an externally applied electric field in a tokamak divertor under reactor relevant conditions [1]. We find further that this technique can direct plasma across a divertor target and then optimally into a pumping aperture by means of the $\vec{E} \times \vec{B}$ drift.

The divertor also defines the confined plasma boundary and influences the central plasma. The high-confinement $\mathrm{H}$-mode is readily produced in diverted plasmas, but only with great difficulty in other configurations. The physics of the $\mathrm{H}$-mode is thought to depend on conditions at or very near the plasma boundary, in particular on the gradient of the radial electric field. The $\mathrm{H}$-mode has had an operational limitation, in that the $\mathrm{H}$-mode plasma adopts a density that is not under operator control. This phenomenon has limited the application of wave and neutral beam current drive to $\mathrm{H}$-mode plasmas, because the natural $\mathrm{H}$-mode density and hence collisionality are too high for efficient current drive. We have used $\vec{E} \times \vec{B}$ divertor pumping to reduce collisionality (reduce density and increase temperature) in ELMing $\mathrm{H}$-mode plasmas. Therefore, low collisionality $\mathrm{H}$-mode plasmas can be expected in DIII-D when cryogenic pumping with high particle removal is installed in the near future.

The DIII-D Advanced Divertor Program (ADP) is a multiinstitutional undertaking to gain increased control over the divertor, particle fluxes, plasma-facing surfaces, the tokamak boundary and indirectly over the core plasma. The ultimate objective is to gain sufficient knowledge to design divertors for the long-pulse, high-power phase of DIII-D and for future tokamaks. In the first phase of the program, reported here, the DIII-D divertor was equipped with a divertor electrode and plenum chamber.

\section{Hardware}

The DIII-D lower divertor was modified by addition of a toroidally symmetric, graphite-armoured, water-cooled divertor electrode having $20 \mathrm{kA}$ capability 21. This electrode was placed at the entrance to a new gas plenum, which will soon contain liquid He cryogenic pumping. These components are illustrated in Fig. 1. The result is an electrically biasable, semi-rlosed divertor.

The design of the new divertor hardware has been de scribed in detail [2]. Here it is sufficient to note that the electrode is electrically insulated laterally from the vacuum vessel by two plasma-facing rings of $\mathrm{BN}$ tiles (Union Carbide, type $\mathrm{HBC}$ diffusion bonded $\mathrm{BN}$ ). The lower and outer electrode surfaces are insulated by mica and $\mathrm{Al}_{2} \mathrm{O}_{3}$ pieces. Electrical power is supplied between the electrode and the metal vacuum vessel. All vacuum vessel surfaces that interact with plasma are covered with graphite tiles, all of which are in electrical contact with the vessel. The electrodes are not heated and do not reach temperatures during operation at which therminnic emission is important. Four toroidally distributed feed conductors are used to ensure that local magnetic errors are small, even at the $20 \mathrm{kA}$ design maximum electrode current. To date the electrode has applied up to $12 \mathrm{kA}$ and $550 \mathrm{~V}$ to diverted plasmas.

Divertor diagnostics include: electrode voltage and current measurements; an array of current monitors to measure current into selected vacuum vessel tiles (tile current arrav); three magnetically shielded, fast response ionization pressure gauges located in the plenum, under the divertor $X$-point, and in an opening to the main torus just above the plenum: IR and filtered visible TV cameras viewing the divertor from above; a filtered visible TV camera viewing the divertor region tangentially: $\mathrm{H}_{\alpha}$. filtered photodiodes viewing the divertor and wall: and a new 


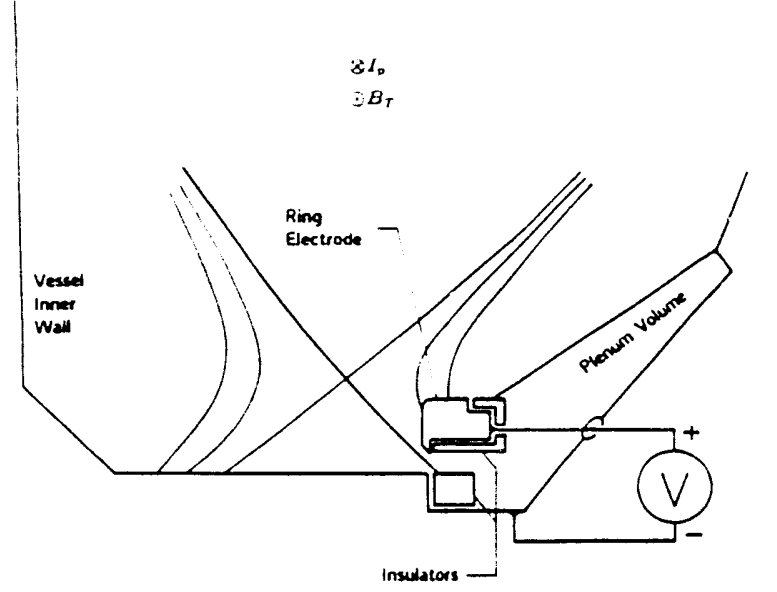

Fig. 1. The DIII-D divertor electrode and pumping plenum. Normal toroidal magnetic field and plasma current directions are indicated. The major axis is to the left.

array of Langmuir probes in the divertor floor. Neither the inner electrode face nor the plenum entrance are viewed or sampled by the present set of diagnostics, except by the tangential TV.

The separatrix strike positions are controlled by the $\mathrm{X}$-point location, which in turn is controlled by the current distribution in the lower poloidal field shaping coils. The outer strike position can be varied smoothly from the middle of the divertor floor to the upper surface of the ring electrode. The separatrix location is calculated from measured magnetic fields and fluxes around the plasma by the EFIT MHD equilibrium fitting code, modified to include non-zero plasma current in the SOL $[3]$.

\section{Semi-Closed Divertor}

The dependence of the plenum gas static pressure on separatrix position was studied by sweeping the $\mathrm{X}$-point slowly in the radial direction while maintaining otherwise unvarying plasma conditions. The electrode was kept at vessel potential. This experiment is illustrated in Fig. 2. The plenum gas pressure increases as the separatrix nears the entrance aperture. The maximum pressure occurs when the separatrix is within about $1 \mathrm{~cm}$ of intercepting the lower inside corner of the electrode. (1 cm is approximately the uncertainty of the EFIT calculation and is also approximately the width of the lines used in the figure to draw the separatrix.) The pressure then decreases rapidly with

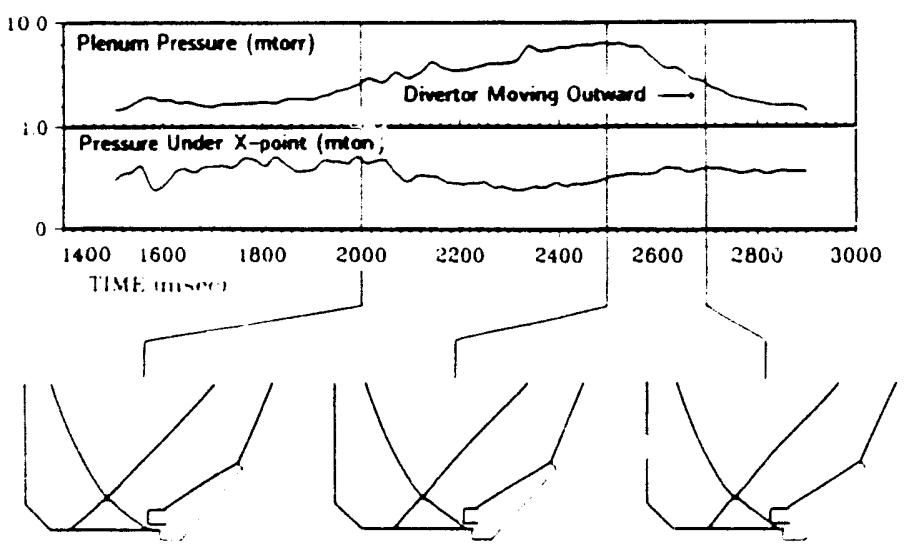

Fig. 2. Plenum and $X$-point gas pressures during a slow outward divertor sweep for the divertor electrode at vessel potential (bias $=0 \mathrm{~V}$ ). additional outward displacement. Pressures under the X-point and above the plenum remain low at all times.

Plenum pressure at the optimum (highest pressure) separatrix location depends on several parameters, including plasma density and divertor surface condition. The pressure depends also on neutral beam heating power as shown in Fig. 3 for ELMIing II-mode. Pressures on the order of 10 mtorr are typically obtained. and this will be sufficient for practical high-throughput pumping in DIII-D. Such bigh pressures imply that flux amplification factors $>10$ are operative. To check whether this is reasonable, two cases were simulated by the B2 edge transport code. The code is constrained by matching the available edge Thomson scattering and IRTV divertor heat flux data and yields estimates of particle fluxes at the entrance aperture, which are used by the DEGAS Monte Carlo neutrals code to caiculate the plenum pressure. The calculations give pressures of 5 mtorr for $7.5 \mathrm{MW}$ heating and $12 \mathrm{mtor}$ for $14 \mathrm{MW}$, in reasonable agreement with experiment.

\section{Elactrical Divertor Particle Control}

The effect of divertor bias has been studied in Ohmic, L-mode and ELMing H-mode single-null diverted discharges. For the standard DIII-D toroidal magnetic field and plasma curront directions, indicated in Fig. 1, negative electrode potential relative to the vacuum vessel increases the plenum gas pressure and decreases particle recycling at the inner divertor, the inner wall and the (outer) limiter. On the other hand, positive bias potential decreases the plenum gas pressure and increases recycling at the inner divertor, inner wall and limiter. These effects are qualitatively present, whether the separatrix strikes the electrode or the vessel floor, so long as it is close enough for the divertor plasma to interact with the biased electrode. Gas pressure remains low under the $\mathrm{X}$-point at all times. The bias electrical power in these experiments is typically $1 \mathrm{MW}$. Some of this power is radiated, while the remainder appears at the divertor electrodes as heat. Electrode operation does not contribute to plasma impurities.

Figure 4 shows the dependence of the peak plenum gas pressure, measured during slow divertor sweeping as in Fig. 2, as a function of electrode potential. Data are presented for $\mathrm{H}$-mode

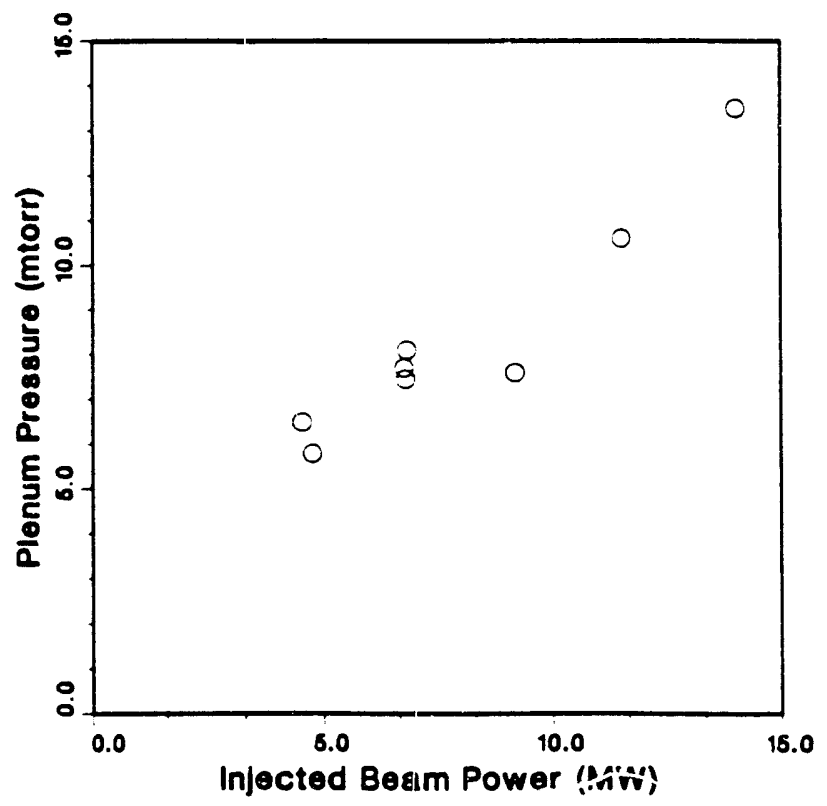

Fig. 3. Plenum gas pressure at optinum position vs. neutral beam power during ELMing $\mathrm{H}-$ mode at $1 \mathrm{MA}, 2.1 \mathrm{~T}$, and $\mathrm{OV}$ bias. 
plasmas at two heating powers and for medium density $\mid \bar{n}_{e}=$ $2.3 \sim 2.5 \times 10^{19} \mathrm{~m}^{-3}$ ) Ohmic and L-mode plasmas, ail at $B_{T}=$ $2.1 \mathrm{~T} . I_{p}=1$ MA and standard field directions. The dependence on bias potential appears to be monotonic in all cases where data is available. Positive (negative) bias decreases (increases) the pressure. Reversal of the toroidal field direction reverses the roles of positive and negative bias, indicating a role for $\vec{E} \times \vec{B}$ drifts.

The observed changes to the particle recycling and plenum pressure are qualitatively consistent with the expected consequences of bias-induced drift velocity, $\vec{v}_{E}=\vec{E} \times \vec{B}_{T} / B_{T}^{2}$, in the SOL $[4,5]$. As illustrated in Fig. 5, which is drawn for standard DIII-D field directions, the bias voltage establishes a poloidal electric field $E_{P}$ within the magnetic surfaces contacting the electrode, and the resulting "radial" $v_{E}$ would yield the observed recycling changes at the inner and outer walls. Figure 5 also shows that a "radial" electric field $E_{r}$ is established normal to the biased magnetic surfaces. W.en the separatrix strikes below the electrode, $\vec{E}_{r} \times \vec{B}_{T}$ produces a poloidal How in the SOL between the separatrix and the biased surface, directing plasma toward the inner (outer) divertor for positive (negative) bias potential, respectively. This is again in qualitative agreement with the recycling and plenum pressure observations.

The electric potential distribution becomes more complicated when the separatrix strikes the electrode. The potential distribution is shown qualitatively for this case in Fig. 6. Large $E_{r}$ appears as a consequence of potential jumps across a thin boundary layer near the separatrix. (Just inside the separatrix $E_{P}$ must be small, so the potential difference between large and small major radius SOL must appear across a boundary layer.) Large $E_{r}$ also appears in boundary layers separating biased magnetic surfaces from surfaces contacting insulators at one end and the vessel at the other. (Leakage of current across $\vec{B}$ is small, so such surfaces remain close to vessel potential.) As seen in Fig. 6, the $\vec{E} \times \vec{B}_{T}$ flow, which is along equipotentials, drives plasma across the SOL, the divertor separatrix and the "arch" surfaces below the $\mathrm{X}$-point. Then, the large $E_{\tau}$ in the boundary layer grazing the lower inside corner of the electrode drives the plasma rapidly into the plenum entrance. Although plasma striking the electrode before reaching the plenum entrance is neutralized,

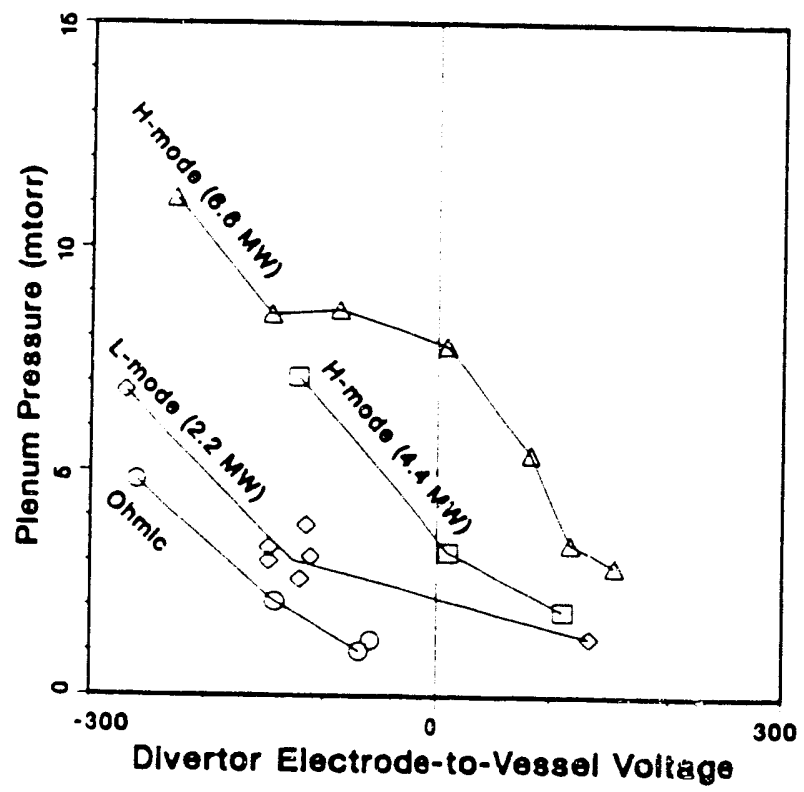

Fig. 4. Plenum gas pressure at optimum position vs. bias for four plasma conditions. Ohmic and $\mathrm{L}-$ mode chord average electron densities are $2.3 \sim 2.5 \times 10^{19} \mathrm{~m}^{-3}$. All points are for 1 MA and $2.1 \mathrm{~T}$.

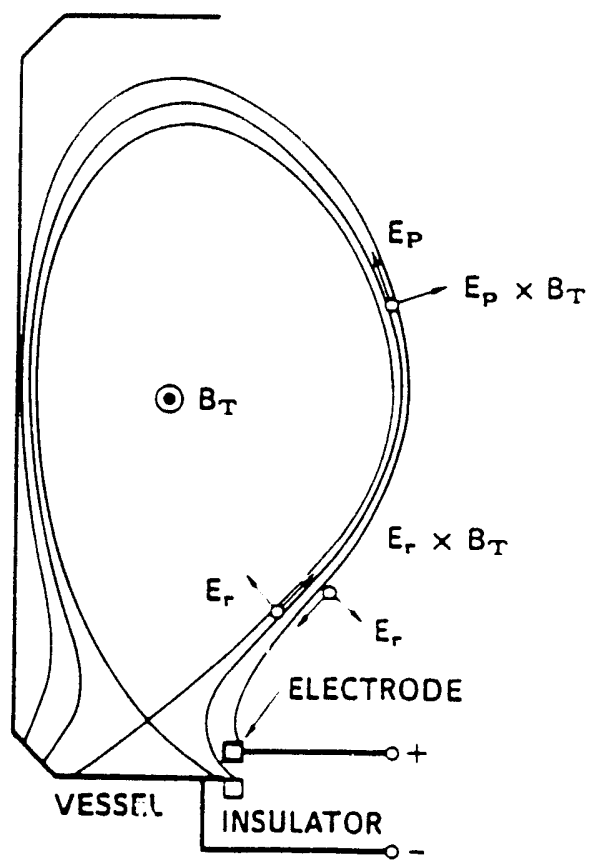

Fig. 5. Illustration of $\vec{E}_{P} \times \vec{B}_{T}$ radial flow and $\vec{E}_{r} \times \vec{B}_{T}$ poloidal flows when the separatrix strikes below the divertor electrode in DIII-D.

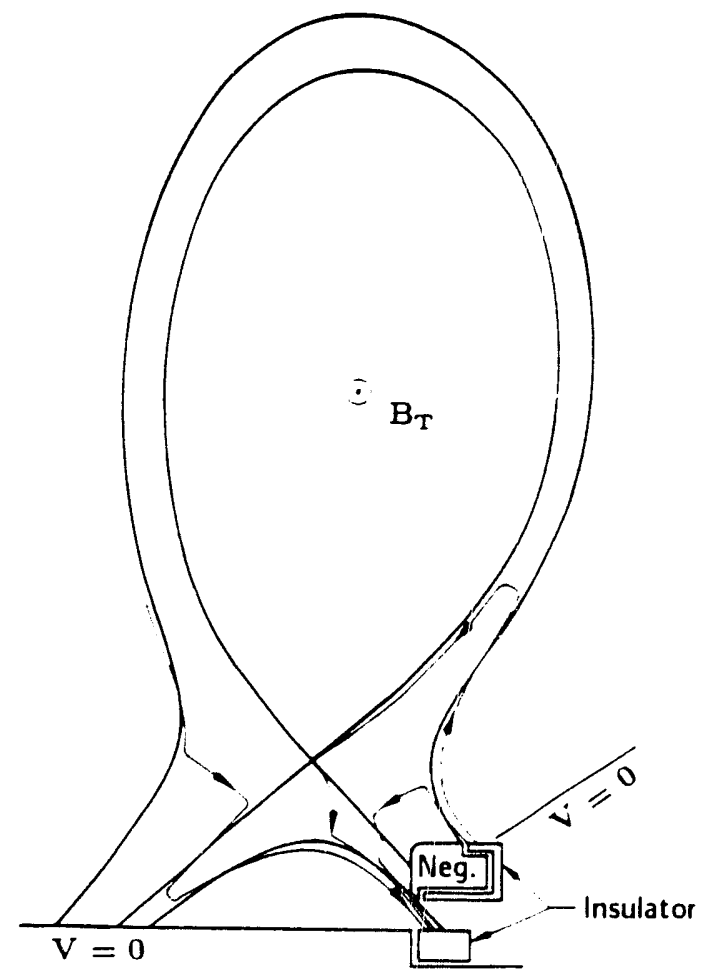

Fig. 6. Qualitative illustration of equipotentials and resulting $\vec{E} \times \vec{B}_{T}$ flows when the separatrix strikes the divertor electrode in DIII-D.

most of the neutral atoms are reionized near the neutralization site by the dense divertor plasma, and the reborn ions are subject to the same drifts. Therefore, all outer SOL ions, except those that get buried in electrode and floor material, eventually reach the plenum entrance at the optimum position for pumping. Experincinally this piucess reduces the sensitivity of the plenum 
pressure dependence on separatrix strike position. most notably when the separatrix strikes the electrode. Figure 7 shows that even when the separatrix struck the upper inside corner of the electrode, $i \mathrm{~cm}$ above the top of the plenum entrance aperture, the baffle pressure with bias was almost as high as the pressure for the separatrix optimaily positioned in the aperture without bias (points from Fig. 3). When the separatrix is in the high position, the pressures with bias are about four times higher than those without.

The biased divertor acts as an $\vec{E} \times \vec{B}$ plasma pump. Let there be a potential difference $V$ applied across a plasma gap of width $w$. Let the pump cross section be $L w$, where $L$ is the dimension in the magnetic field direction. Then, the pump speed is

$$
S_{E}=L w v_{E}=L w E / B_{T}=L V / B_{T} \text {, }
$$

where $V=\int \vec{E} \cdot d \vec{w} \approx w E$. Note that the $v_{r}$ and $v_{P}$ pumping speeds are approximately the same. For the experiments described above, $L=2 \pi R \approx 10 \mathrm{~m}, V / B \approx(200 \mathrm{~V}) /(2 \mathrm{~T})=$ $100 \mathrm{~m}^{2} / \mathrm{s}$, so $S_{E} \approx 10^{3} \mathrm{~m}^{3} / \mathrm{s}$. The DIII-D plenum aperture speed for $10 \mathrm{eV} \mathrm{D}+$ is also $\approx 10^{3} \mathrm{~m}^{3} / \mathrm{s}$ for $B_{\mathrm{p}} / B_{T}=1 / 4$ at the aperture.

\section{H-Mode Density Control}

The steady state plasma density during $\mathrm{H}$-mode in DIII-D is proportional to current and depends on little else. The density cannot be varied appreciably by normal operational pro cedures. However, modest density changes were observed in ELMing $\mathrm{H}$-mode plasmas during strong divertor bias, as seen in Fig. 8. For normal field directions, negative bias reduced $\bar{n}_{e}$ and vice versa. The density changes were accompanied by reciprocal changes in the volume-averaged temperature (average of $T_{e}$ and $T_{i}$ ) such that the total energy and energy confinement time remained nearly constant. At present there is no fast active pumping in DIII-D, but gettering, by the divertor tiles and other vessel surfaces, removes some particles from circulation. There has been no indication of appreciable gettering by the plenum walls, which were baked to $\sim 300^{\circ} \mathrm{C}$ but not exposed to plasma bombardment. The deuterium content of the $1.0 \mathrm{~m}^{3}$ plenum volume is about four times the change in deuterium content of the $20 \mathrm{~m}^{3}$ plasma in Fig. 8 . Therefore, it is likely that the bias potential altered net recycling. Definitive tests of $\mathrm{H}$-mode density control will be possible once active cryogenic pumping is installed in the plenum.

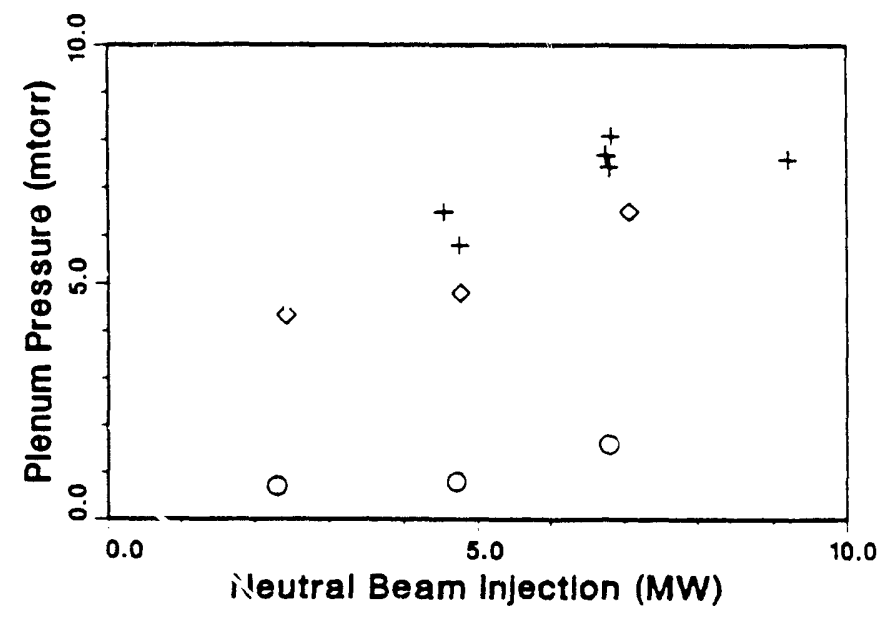

Fig. 7. Plenum gas pressure vs. neutral beam power dur. $z$ ELMing $\mathrm{H}$-mode for three divertor conditions: + pressure at optimum separatrix position, zero bias points from Fig. 3: ○ separatrix striking upper inside corner of electrode at $-90 \sim-170 \vee$ bias; $\square$ separatrix striking as in diamond case, but zero bias.

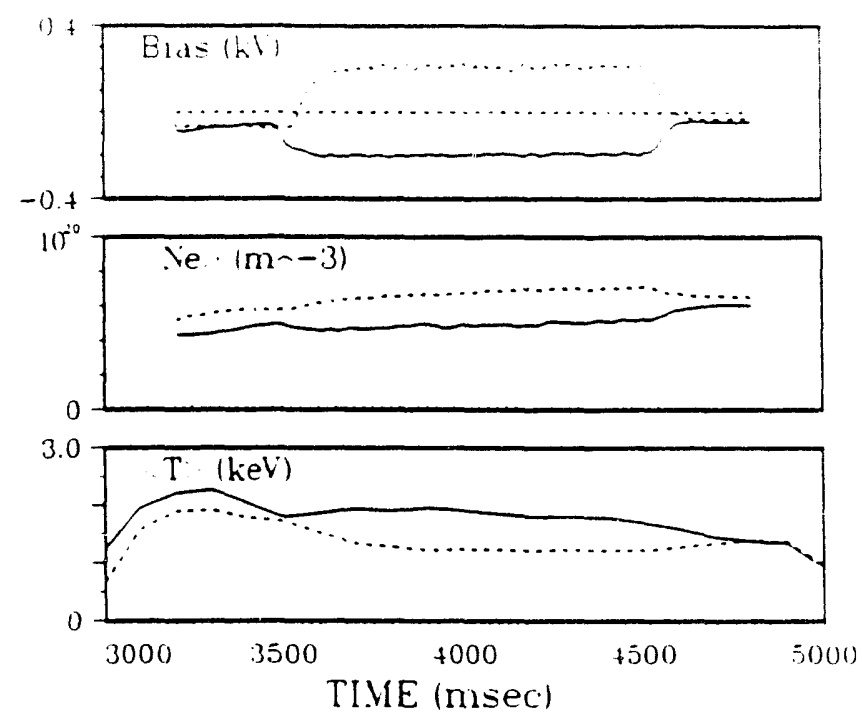

Fig. 8. Bias, lotential, average density and average temperature during ELMing $\mathrm{H}-\mathrm{mr}$. de at $1.2 \mathrm{MA}, 2.0 \mathrm{~T}$ and $12 \mathrm{MW}$ beam heating.

\section{Conclusions}

Experiments to date show excellent prospects for particle control. Neutral gas pressure in the plenum reaches $\geq 10$ mtorr (sufficient for efficient particle removal) during ELMing H-mode, when the separatrix is optimally positioned at the entrance. Selfconsistent models are needed to account for such high pressure. Such passively developed high pressures are especially sensitive to separatrix position and plasma density. Divertor bias can shift the SOL particle flow between divertors by the $\vec{E} \times \vec{B}_{T}$ drift. In the DIII-D geometry the $\vec{E} \times \vec{B}_{T}$ drift also transports particles across the SOL and optimally into the plenum entrance when the separatrix strikes the electrode. Therefore, the divertor bias acts as a geometry-insensitive bigh capacity pump to drive plasma into the plenum aperture. Some possible applications are: to reduce vacuum pumping requirements for steady state plasmas; to exhaust plasma from low density plasmas; to establish low collisionality, low density $\mathrm{H}$-mode plasmas for current drive; and to make plasma exhaust insensitive to divertor geomet? esnecially to the variable geometry of swept divertors.

\section{Acknowledgment}

This work was sponsored by the U.S. Department of Energy under Contract Nos. DE-AC03-89ER51114, DE-AC0584OR21400, W-7405-ENG-48, and DE-AC03-76DP00789.

\section{References}

[1] M.J. Schaffer et al., "Electric Field Convection of Plasma and Heat," General Atomics Report GA-A20474 (1991), submitted to Phys. Rev. Lett.

[2] P.M. Anderson et al., Fusion Technology 1990, 336 (1991).

(3) L.L. Lao T.H. Jensen, "Magnetohydrodynamic Equilibria in Elongated Tokamaks after Loss of Vertical Stability," General Atomics Report GA-A20101 (1991), submitted to Nuclear Fusion.

[4] E.J. Strait, D.W. Kerst, and J.C. Sprott, Phys. Fluids 21, 2342 (1978).

[5] E.J. Strait, Nucl. Fusion 21, 943 (1981). 

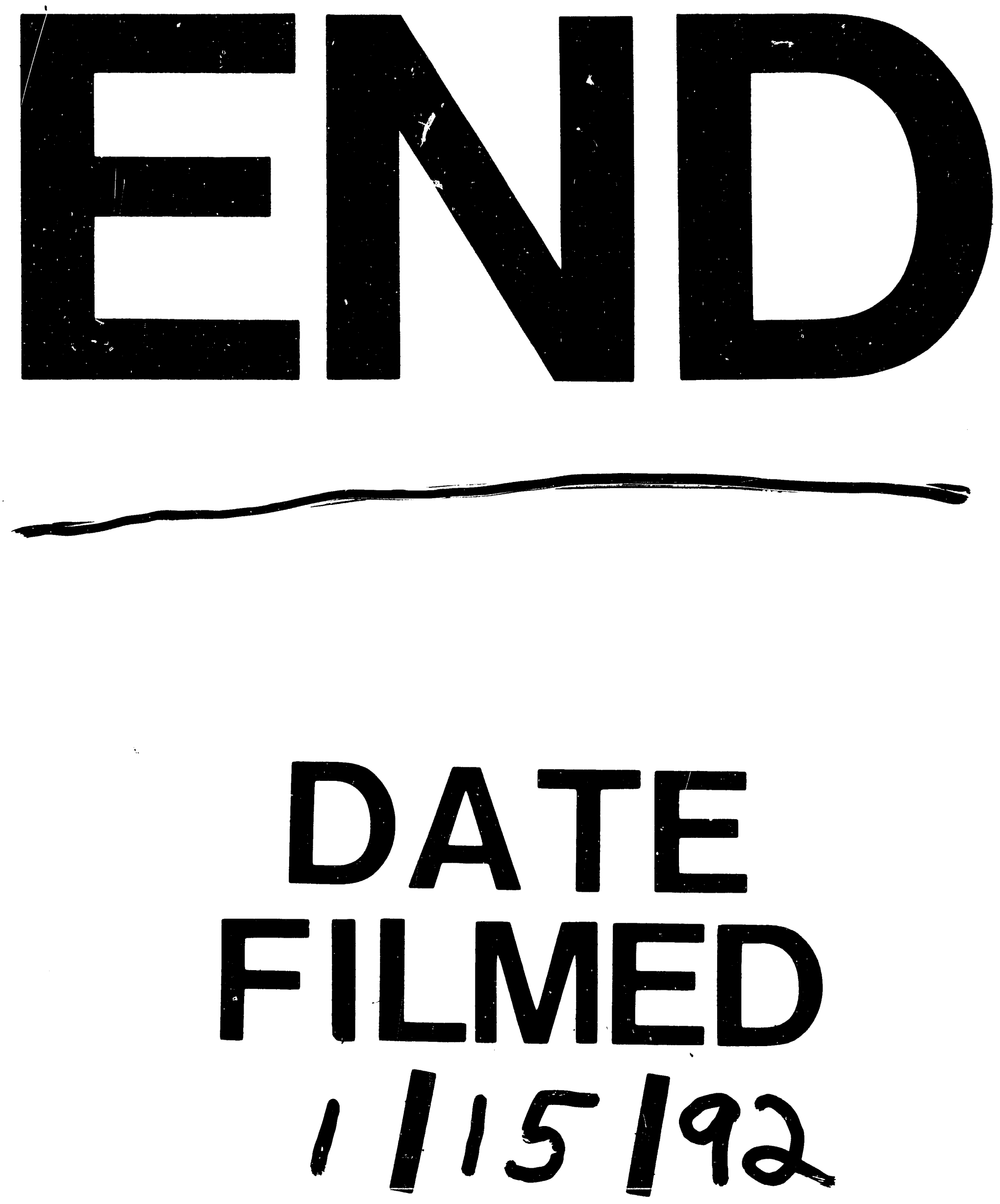

$I$ 
